Research Article

\title{
Study of prescription pattern and adverse drug reactions in patients with cervical cancer in tertiary care teaching institute
}

\author{
Ankita Sunilrao Jire ${ }^{1}$, Chaitali S. Bajait ${ }^{1}$, Vijay K. Mahobia ${ }^{2}$, \\ Vijay M. Motghare ${ }^{1}$
}

${ }^{1}$ Department of Pharmacology,

${ }^{2}$ Department of Radiotherapy

Government Medical College,

Nagpur, Maharashtra, India

Received: 03 June 2016

Revised: 06 July 2016

Accepted: 08 July 2016

*Correspondence to:

Dr. Ankita Sunilrao Jire,

Email: jire.ankita@gmail.com

Copyright: () the author(s), publisher and licensee Medip Academy. This is an openaccess article distributed under the terms of the Creative Commons Attribution NonCommercial License, which permits unrestricted noncommercial use, distribution, and reproduction in any medium, provided the original work is properly cited.

\begin{abstract}
Background: Cervical cancer is the second most common cancer in women especially in developing countries. In India, it is estimated that 1, 22, 644 new cases of cancer cervix occur every year. Incidence rate is 22 per lac population and mortality rate is 12.4 per lac population. The objective of this study was to study the prescription pattern and adverse drug reactions (ADRs) in patients with cervical cancer.

Methods: Twenty five patients of cancer cervix Stage (IIa to IVb) receiving chemotherapy were enrolled in the study after written informed consent of patients. Approval was obtained from institutional ethics committee. It was cross sectional, observational study. Prescriptions were analysed for no. of drugs prescribed, time interval between two cycles, no. of cycles of chemotherapy. Any ADR observed by patient or treating physician was noted and causality was assessed by Naranjo's algorithm. Preventability and severity of ADRs were assessed by modified Schumock and Thornton scale, modified Hartwig and Siegel scale respectively.

Results: Twenty five patients were enrolled with mean age 52.24 \pm 8.66 years and mean weight $51.76 \pm 5.88 \mathrm{~kg}$. $84 \%$ patients were on combination chemotherapy. Percentage of anticancer drugs prescribed were: cisplatin (72\%); paclitaxel (40\%); 5FU (36\%); carboplatin (32\%); gemcitabine (4\%). Chemotherapeutic drugs were given at 3 weekly intervals for 6 cycles. ADR observed were nausea (76\%), vomiting $(40 \%)$, alopecia $(32 \%)$, headache $(12 \%)$, bodyache $(12 \%)$, anorexia $(12 \%)$, diarrhoea $(8 \%)$ and malaise $(4 \%)$. Causality assessment of ADR by Naranjo's algorithm showed $89.8 \%$ probable and $10.2 \%$ possible reactions. According to modified Schumock and Thornton scale, 26.5\% reactions are 'not preventable' however $73.5 \%$ are 'definitely preventable'. According to modified Hartwig and Siegel scale, $75.5 \%$ were 'mild level 1 'severity however $24.5 \%$ were 'moderate level 3' severity.

Conclusions: Among patients with CA cervix, cisplatin was most commonly prescribed drug. Nausea was most common ADR which is of 'mild level 1' severity.
\end{abstract}

Keywords: Cancer cervix, Chemotherapy-prescription pattern, ADR

\section{INTRODUCTION}

Cervical cancer is the second most common cancer in women especially in developing countries. In India, it is estimated that $1,22,644$ new cases of cancer cervix occur every year. Incidence rate is 22 per lac population and mortality rate is 12.4 per lac population. ${ }^{1}$ Drugs most often used to treat cervical cancer include: cisplatin, carboplatin, paclitaxel, 5 flurouracil (5FU), gemcitabine. Often combinations of these are used.
Drug utilization is defined as "The marketing, distribution, prescription and use of drugs in a society, with special emphasis on the resulting medical, social and economic consequences". 2 The study of prescription patterns is a component of medical audit that monitors and evaluates prescription practices and recommends necessary modifications to achieve rational drug use. In individual patients rational drug use implies prescription of a well-documented drug in optimal dose for right indication at an affordable price. ${ }^{3}$ 
World Health Organization (WHO) defines ADR as "Any response to a drug which is harmful, inadvertent and occurs at doses used in man for prophylaxis, diagnosis or therapy". ${ }^{4}$ The data on ADRs has shown that it has become one of top ten causes of death in the US yearly and represents a major clinical problem for humans and healthcare costs. 5,6

Much of the documented evidence on drug utilization pattern and ADRs comes from developed countries. There is a need for effective pharmacovigilance in India owing to absence of Indian data on adverse effects and the genetic diversity of the Indian population. Hence the present study was carried out with following aims.

\section{METHODS}

The present cross-sectional, observational study was conducted in radiotherapy department after approval from Institutional ethics committee for 2 months period. Demographic profile, clinical details and prescription data was collected in specially designed proforma and analysed after obtaining written informed consent from patients. Prescriptions were analysed for number of drugs prescribed, time interval between two cycles, no. of cycles of chemotherapy. Any ADR observed by patient or treating physician was noted in detail. Cancer cervix patients, who were receiving cancer chemotherapy under any standard regimen, were included for the study. The patients received cancer chemotherapy as per the assessment of the treating physician. No changes in the treatment decision, schedule or duration were made as a part of the study.

All the patients received pre-medication with intravenous ranitidine, dexamethasone and ondansetron to avoid emesis, as chemotherapeutic drugs are highly emetogenic drugs. The collected information was documented in the case record form and analysed for demographic details, drug details, causality, preventability and severity of adverse effects. Causality was assessed by Naranjo's algorithm. ${ }^{7}$ Preventability was assessed by modified Schumock and Thornton scale. ${ }^{8}$ The severity of ADRs was assessed by modified Hartwig and Siegel scale. ${ }^{9}$

In Naranjo's algorithm, a questionnaire designed by Naranjo et al consists of objective questions with three types of responses - yes, no or do not know. Scores are given accordingly and the drug reaction can be classified as definite, probable or possible. The modified Schumock and Thornton scale classifies ADRs as definitely preventable, probably preventable and not preventable based on a set of questions for each level. The modified Hartwig and Siegel scale classifies severity of ADR

as mild, moderate or severe with various levels according to factors like requirement for change in treatment, duration of hospital stay, and the disability produced by the adverse drug reaction.
No invasive investigation was undertaken or suggested to the treating physician by the investigator as a part of the study. The drug effects which were described by the patients and effects which were diagnosed and reported by the physician were documented.

\section{RESULTS}

Twenty five patients were enrolled with mean age $52.24 \pm 8.66$ years and mean weight $51.76 \pm 5.88 \mathrm{~kg}$. Figure 1 shows the education profile of the patients.

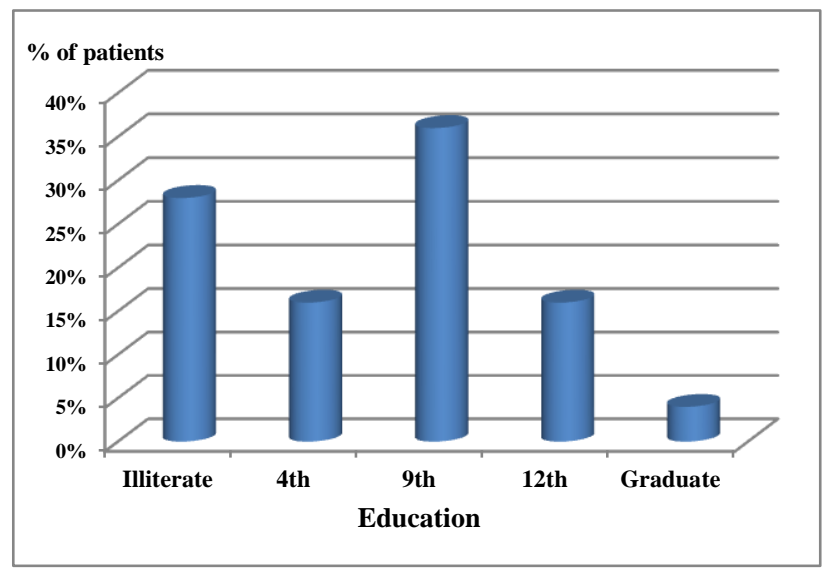

Figure 1: Education profile of the patients having cervical cancer $(\mathrm{N}=25)$.

Percentage of anticancer drugs prescribed were: cisplatin (72\%); paclitaxel (40\%); 5 FU (36\%); carboplatin (32\%); gemcitabin $(4 \%)$. Cisplatin was most commonly used drug. Five patients were on cisplatin therapy alone and 12 patients were receiving cisplatin along with other anticancer drugs (paclitaxel, 5FU, gemcitabin) (Figure 2).

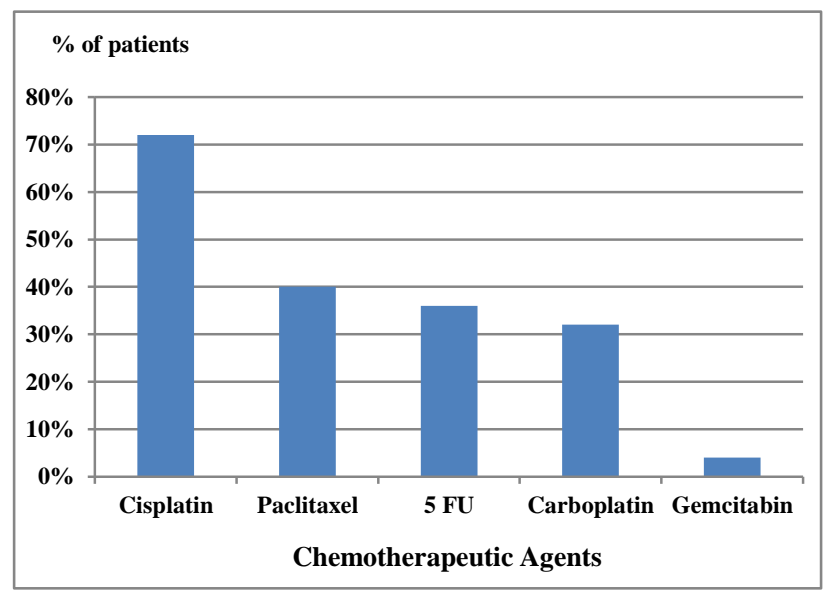

Figure 2: Prescription pattern of chemotherapeutic agents in patients of cervical cancer $(\mathrm{N}=25)$.

Chemotherapeutic drugs were given at 3 weekly intervals for 6 cycles. All of these drugs are included in list of essential medicines. 
The ADRs observed with these chemotherapeutic agents were nausea $(76 \%)$, vomiting $(40 \%)$, alopecia $(32 \%)$, headache $(12 \%)$, bodyache $(12 \%)$, anorexia $(12 \%)$, diarrhoea (8\%), and malaise (4\%) (Figure 3).

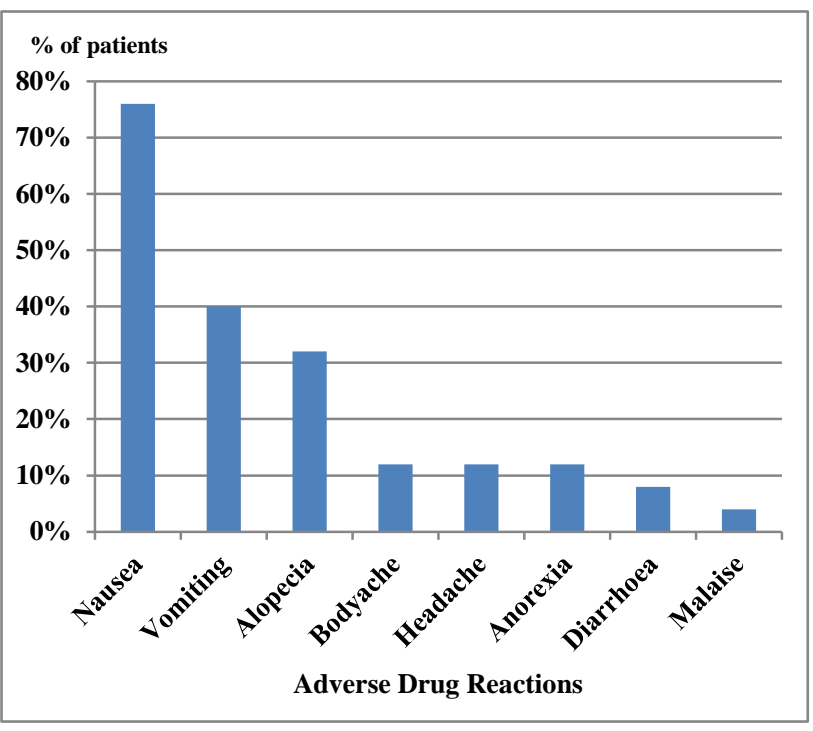

Figure 3: Incidence of adverse drug reactions in patients of cervical carcinoma $(\mathrm{N}=25)$.

The adverse drug reaction reports were obtained by regular questioning of patients by the investigator. Assessment of causality by Naranjo algorithm indicated that $89.8 \%$ of the reactions belong to the category "probable" with score ranging from 5-8, followed by $10.2 \%$ of reactions of the category "possible" with score ranging from 1-4.There were no "certain" reactions as rechallenge was not attempted in any of the patients. However, the grade of causality for each ADR remained low due to presence of co-administered drugs.

Assessment of preventability of the ADR was done based on modified Schumock and Thornton scale. Most of the ADRs belonged to the category of "definitely preventable". However, reactions like alopecia, anorexia, diarrhoea belonged to the category of "not preventable".

Based on modified Hartwig and Siegel scale of severity assessment, most of the reactions were of less severity categorized as "mild level 1" severity, except for vomiting and diarrhoea which were categorized as "moderate level 3" severity.

\section{DISCUSSION}

In the present study, we analysed drug utilization pattern and occurrence of ADRs in cervical cancer patients which is highly prevalent in Indian women.

In this study, Most of patients were on combination chemotherapy which is supported by the previous studies conducted by Taneja et al. Cisplatin was commonly used anti-neoplastic agent as in previous study by John et al.
Some of the well documented ADRs of this drug include nausea, vomiting, renal toxicity, ototoxicity, peripheral neuropathy, hypersensitivity reactions and electrolyte disturbances. Most of the ADRs documented in this study comprised one or more of these reactions. Although adequate pre-medication with parenteral dexamethasone, ranitidine and ondansetron were given to each patient, the frequency of nausea and vomiting remained high due to high emetogenic potential of cisplatin. ${ }^{10}$ These drugs may induce vomiting by both a central action on the chemoreceptor trigger zone (CTZ) and a peripheral action on the gastrointestinal tract. The dominant receptors in the CTZ located in the floor of the fourth ventricle are serotonin type 3 (5-HT3) and dopamine type 2 (D2). ${ }^{11}$ As serotonin receptors in the brain are involved in the mechanism of acute onset vomiting, ondansetron has a definite role in its prevention. ${ }^{12}$

The most frequent adverse effects include nausea, vomiting and alopecia. The study has demonstrated the need to improve the management of nausea and vomiting, since the rates of prevention of these expected adverse effects of cisplatin were poor. Some of the rarer reactions include headache, malaise, diarrhoea, anorexia. In this study, we observed $32 \%$ patients were having alopecia as ADR in contrast to study of Kamil et al in which alopecia was the most common ADR. Hair loss has been rated as one of the most distressing side effect of chemotherapy, along with nausea and vomiting. ${ }^{13}$ Out of 8 patients who developed alopecia 6 were on carboplatin and paclitaxel combination and only 2 were on cisplatin therapy. So hair loss seems to be more common with carboplatin and paclitaxel combination. ${ }^{14}$

Diarrhoea was seen in $8 \%$ of the patients which can occur due to mucosal cell toxicity. Animal studies have demonstrated the effect of cisplatin causing specific mitochondrial oxidative DNA damage in gastro intestinal mucosal cells and increased gastro intestinal permeability, an indicator of toxicity. ${ }^{15}$ According to values of complete hemogram taken pre and post treatment, there were no reports of hematological disturbances.

In present study, most of the ADRs had been identified as probable by Naranjo's algorithm supported by Surendiran et al. There were no "certain" drug reactions as the patients were not subjected to re challenge of the drug. There were no "unlikely" drug reactions as the investigator was trained in methods of pharmacovigilance and such complaints were avoided.

Majority ADRs were preventable. Common ADRs like nausea and vomiting can be effectively controlled. This brings out the possible toxicity that the treating physician should anticipate and counsel the patient adequately prior to starting of therapy. Chemotherapy related nausea and vomiting remains a problem in many patients despite the use of 5-HT3 receptor antagonists and dexamethasone. According to study by D.G. Warr use of NK 1 receptor antagonist aprepitant as add on may reduce the likelyhood 
of vomiting and retching associated with use of chemotherapeutic agents. $^{12}$ So modification in the management of nausea and vomiting is needed.

Most of the reactions were of mild severity and there would be no strong indication to change or withhold the drug for mild adverse effects.

Finally to conclude, In the present study, cisplatin was the most commonly used chemotherapeutic agent for cervical cancer and nausea was the most common ADR which is of 'mild level 1' severity. Thus present study emphasizes the need to improve management of ADR and pharmacovigilance for better outcome of cervical cancer treatment in future.

\section{ACKNOWLEDGEMENTS}

Authors would gratefully acknowledge Dr. A. K. Diwan, Associate professor and head, Department of Radiotherapy, for giving permission to collect data from patient attending OPD of Radiotherapy department.

Funding: No funding sources Conflict of interest: None declared

Ethical approval: The study was approved by the Institutional Ethics Committee

\section{REFERENCES}

1. Park K. Park's Textbook of Preventive and Social Medicine. $23^{\text {rd }}$ edition. Jabalpur: Banarasidas Bhanot; 2015:388.

2. Bergman U, Grimsson A, Wahba AHW, Westerholm B. Editors studies in drug utilization (methods and applications) Europian Series No. 8. WHO Regional Publications; 1979:1.

3. Srishyla MV, Krishnamurthy M, Nagarani MA, Andrade C, Venketaraman BV. Prescription audit in an Indian hospital setting using the DD concept. Indian J Pharmacol. 1994;26:23-8.
4. Lazarou J, Pomeranz BH, Corey PN. Incidence of adverse drug reactions in hospitalized patients: a meta-analysis of prospective studies. J Am Med Assoc. 1998;279(15):1200-5.

5. Lee A, Thomas SHL. Adverse drug reactions. In: Roger Walker and Clive, Editors. Clinical Pharmacy and Therapeutics $3^{\text {rd }}$ ed. Spain: Churchill Living; 2003:33-34.

6. Nerurkar RP, Nadkar MY, Bichile SK. Need for monitoring adverse drug reactions. J Assoc Physicians India. 1998;46:673-4.

7. Naranjo CA, Busto U, Sellers EM, Sandor P, Ruiz I, Roberts EA, et al. A method for estimating the probability of adverse drug reactions. Clin Pharmacol Ther. 1981;30:239-45.

8. Schumock GT, Thornton JP. Focusing on the preventability of adverse drug reactions. Hosp Pharm. 1992;27:538.

9. Hartwig SC, Siegel J, Schneider PJ. Preventability and severity assessment in reporting adverse drug reactions. Am J Hosp Pharm. 1992;49:2229-32.

10. Jordan K, Sippel C, Schmoll HJ. Guidelines for antiemetic treatment of chemotherapy-induced nausea and vomiting: past, present, and future recommendations. Oncologist. 2007;12:1143-50.

11. Flake ZA, Scalley RD, Bailey AG. Practical selection of antiemetics. Am Fam Physician. 2004;69:1169-74.

12. Warr DG. Chemotherapy- and cancer-related nausea and vomiting. Curr Oncol. 2008;15:S4-9.

13. Yeager CE, Oslen EA. Treatment of chemotherapy induced alopecia. Dermatol Ther. 2011;24:432-42.

14. Pavey RA, Kambil SM, Bhat RM. Dermatological adverse reactions to cancer chemotherapy. Indian $\mathbf{J}$ Dermatol Venerol Leprol. 2015;81:434.

15. Yanez JA, Teng XW, Roupe KA, Fariss MW, Davies NM. Chemotherapy induced gastrointestinal toxicity in rats: Involvement of mitochondrial DNA, gastrointestinal permeability and cyclooxygenase -2 . J Pharm Pharm Sci. 2003;6:308-14.

Cite this article as: Jire AS, Bajait CS, Mahobia VK, Motghare VM. Study of prescription pattern and adverse drug reactions in patients with cervical cancer in tertiary care teaching institute. Int J Basic Clin Pharmacol 2016;5:1594-7. 